\title{
CAN GOOD KAP AMONGST SCHOOL TEACHERS PREVENT H1N1 INFLUENZA? A BEGINNING.
}

Avtar Singh Bansal ${ }^{1}$, R.K. Gupta르, Rajshree R Gupta ${ }^{3}$

\section{HOW TO CITE THIS ARTICLE:}

Avtar Singh Bansal, R.K. Gupta, Rajshree R Gupta. "Can good KAP amongst school teachers prevent H1N1 Influenza? A Beginning". Journal of Evolution of Medical and Dental Sciences 2014; Vol. 3, Issue 03, January 20; Page: 633-640, DOI:10.14260/jemds/2014/1878

ABSTRACT: BACKGROUND: Pune served as hub of H1N1 and recorded maximum deaths in India during 2009 pandemic. Teachers form important part of society which can greatly influence population. AIM: To study knowledge, attitude and practices on H1N1 amongst school teachers in Pune. Study endeavors to bring forth positive practices, which besides benefitting teachers would also translate into disseminating knowledge to students and families, resulting in maximum benefit to society. SETTINGS AND DESIGN: Cross sectional, KAP study amongst school teachers taken was undertaken METHODS: A questionnaire based, cross sectional KAP study was undertaken on 96 teachers from a public school in Pune during June-September 2010. Epi Info version - 2006 was used for data analysis. RESULTS: While most were well aware of H1N1 basics, 40\% didn't know danger signs/ complications. Knowledge on prevention demanded attention. $45 \%$ believed that H1N1 isn't a big problem. About 1/3rd couldn't appreciate importance of isolation or use of mask. Only $64.6 \%$ would stay home on having flu. One fifth believed in wearing mask at workplace and about half in keeping distance of $1 \mathrm{~m}$ from patients. About $60 \%$ didn't believe in avoiding crowed places. $15 \%$ won't wash hands. About $17 \%$ wouldn't stay home or visit doctor if suffering from cold. Half would not take medicines. CONCLUSION: Fact that 'good' knowledge dwindled to 'fair' attitudes, which in turn didn't translate into desirable robust practices, is alarming. Efforts must be directed towards enhancing knowledge, improving attitudes and imparting behavior changes for desirable practices, which will bring change in society. It's recommended that IEC emphasizing prevention must be undertaken immediately.

KEY WORDS: H1N1 Influenza, KAP, Teachers, Pune.

INTRODUCTION: On 11 June 2009 WHO declared H1N1 as pandemic phase 6. The first case in India was reported on 15th May 2009 at Hyderabad. Pune is a large industrial city with vulnerable population it holds a special place in spread of H1N1 being the worst hit serving as hub of H1N1, registering the first death in India on $6^{\text {th }}$ July 2009 and also the highest number of deaths in the country.

Schools have the potential to become explosive centrifugal outbreak centers due to their large young population, close social contact and permeable boundaries. Additionally, student behavior is often divergent from non-student adult populations. Hence, understanding the outbreak and its management in such institutions is essential to minimize impact of pandemic influenza in both the institution and its surroundings. Moreover, it is well-known that students blindly follow teacher's advice. With this background the role of teachers is of paramount importance in disseminating knowledge on prevention of H1N1 influenza among students. Here comes the importance of not only correct knowledge about H1N1 amongst teachers, but also having a sound attitude and exemplary practices that could be emulated by students. 
This study was conducted to examine the knowledge, attitudes and practices of teachers towards H1N1 influenza in a Public School that went through the turmoil in 2009, to identify gaps in these areas and to recommend suitable measures for effective prevention in future.

MATERIALS AND METHODS: The study was undertaken from June to September 2010 at an elite higher secondary Public School in Pune city with a teacher population of 120. A semi-structured knowledge, attitude and practice (KAP) questionnaire on H1N1 influenza was designed and pretested.

Considering standard statistical protocols, a sample size of 96 was estimated. A stratified random sample was taken from amongst school teachers which belonged to either of these three categories: Primary, Trained Graduate or Post Graduate Teachers. A pilot study was undertaken to validate study protocol. Aim and modality of study was explained to all the teachers and were explained to mark questionnaires as per instructions. Suitable statistical analysis was done using Epi info 2006 software.

RESULTS: KNOWLEDGE ABOUT H1N1 INFLUENZA. While most teachers were well aware of basic aspects of $\mathrm{H} 1 \mathrm{~N} 1.40 \%$ were unaware of the danger signs and complications. Most subjects knew about N95 mask about half didn't know, how to use it correctly. Only less than two third appreciated importance of preventive measures and more than $3 / 4^{\text {th }}$ appreciated the importance of isolating cases. (Table 1).

\begin{tabular}{|c|c|c|c|c|c|c|}
\hline \multirow{2}{*}{ Knowledge } & \multicolumn{2}{|c|}{ Correct Knowledge } & \multicolumn{2}{|c|}{ Incorrect Knowledge } & \multicolumn{2}{|c|}{ Didn't Know } \\
\hline & $\mathrm{N}$ & $\%$ & $\mathrm{~N}$ & $\%$ & $\mathrm{n}$ & $\%$ \\
\hline \multicolumn{7}{|l|}{ Basic Facts } \\
\hline What is swine flu & 85 & 88.5 & 11 & 11.5 & 0 & 0 \\
\hline Causative agent & 92 & 95.8 & 4 & 4.2 & 0 & 0 \\
\hline Infection Source & 84 & 87.5 & 12 & 12.5 & 0 & 0 \\
\hline Transmission route & 90 & 93.7 & 6 & 6.3 & 0 & 0 \\
\hline Availability of vaccine & 90 & 93.7 & 4 & 4.2 & 2 & 2.1 \\
\hline \multicolumn{7}{|l|}{ Clinical Features } \\
\hline System affected & 95 & 98.9 & 1 & 1.0 & 0 & 0 \\
\hline Most susceptible people & 78 & 81.3 & 18 & 18.7 & 0 & 0 \\
\hline Signs /symptoms & 87 & 90.6 & 9 & 09.4 & 0 & 0 \\
\hline Danger signs & 59 & 61.5 & 37 & 38.5 & 0 & 0 \\
\hline Complications & 55 & 57.3 & 41 & 42.7 & 0 & 0 \\
\hline \multicolumn{7}{|l|}{ Prevention } \\
\hline Name popular mask & 84 & 87.5 & 12 & 12.5 & 0 & 0 \\
\hline Correct use of mask & 42 & 43.7 & 31 & 32.3 & 23 & 23.9 \\
\hline Importance of prevention & 59 & 61.5 & 37 & 38.5 & 0 & 0 \\
\hline Importance of isolation & 73 & 76.1 & 23 & 23.9 & 0 & 0 \\
\hline Necessity of vaccine in H1N1 positive & 34 & 35.4 & 49 & 51.1 & 13 & 13.5 \\
\hline
\end{tabular}




\section{ORIGINAL ARTICLE}

ATTITUDES ON H1N1: While most felt that H1N1 is a huge problem and a threat to world, one third felt that problem has been exaggerated. Most believed that wearing a mask plays a role in prevention H1N1 can definitely be prevented and close contact with H1N1 patient must be avoided. Most believed that they will stay home on having flu like symptoms and washing hands with sanitizer was better (Tables 2 and 3).

\begin{tabular}{|l|c|c|}
\hline \multicolumn{1}{|c|}{ Attitude } & $\mathrm{n}$ & $\%$ \\
\hline H1N1 a huge problem: yes & 53 & 55.2 \\
\hline H1N1 an exaggerated problem & 29 & 30.2 \\
\hline Can't comment & 14 & 14.6 \\
\hline & & \\
\hline H1N1 threat to themselves & 15 & 15.6 \\
\hline H1N1 threat to country & 21 & 21.9 \\
\hline H1N1 threat to world & 60 & 62.5 \\
\hline & & \\
\hline Washing hands with sanitizer better than soap water & 63 & 65.6 \\
\hline Washing hands with sanitizer NOT better than soap water & 17 & 17.7 \\
\hline Can't comment & 16 & 16.7 \\
\hline & & \\
\hline H1N1 can kill & 85 & 88.5 \\
\hline H1N1 can't kill & 7 & 7.3 \\
\hline Can't comment & 4 & 4.2 \\
\hline
\end{tabular}

Table 2: General Attitudes

\begin{tabular}{|l|c|c|}
\hline Attitude & n & \% \\
\hline H1N1 can definitely be prevented & 70 & 72.9 \\
\hline H1N1 may be prevented & 17 & 17.7 \\
\hline H1N1 can't be prevented & 0 & 0 \\
\hline Can't comment & 09 & 9.4 \\
\hline & & \\
\hline Close contact with H1N1 must be avoided & 76 & 79.2 \\
\hline Avoiding close contact with H1N1 patient not very important & 1 & 1.0 \\
\hline Avoiding close contact with H1N1 patient sometimes, is good enough & 19 & 19.8 \\
\hline & & \\
\hline Mask doesn't play role in controlling infection & 5 & 5.2 \\
\hline Mask may play some role & 23 & 23.9 \\
\hline Mask plays a role & 68 & 70.8 \\
\hline & & \\
\hline Will NOT stay home on having flu & 8 & 8.3 \\
\hline Will stay home only if flu increases & 26 & 27.1 \\
\hline Will stay home on having flu & 62 & 64.6 \\
\hline
\end{tabular}

Table 3: Attitude on Prevention of H1N1 
PRACTICES ON H1N1: Most subjects believed in keeping a handkerchief, covering their mouth/nose while coughing/sneezing or when someone coughs. About two third believed in avoiding public places during epidemics. Use of mask didn't find much preference while on work, most would use it when visiting a patient. About half the teachers believed in keeping a safe distance from flu patients. Most subjects believed in washing hands immediately on coming back home and consciously avoid touching door handles. Majority didn't believe in kissing or shaking hands with close friends. Some teachers would never stay home or visit a doctor even if they suffer from cold. Half the respondents would always take prescribed medicines. Most would educate others on prevention and treatment issues. (Tables 4, 5 and 6)

\begin{tabular}{|l|c|c|c|c|c|c|}
\hline \multirow{2}{*}{\multicolumn{1}{|c|}{ Practices }} & \multicolumn{2}{|c|}{ Always } & \multicolumn{2}{c|}{ Sometimes } & \multicolumn{2}{c|}{ Never } \\
\cline { 2 - 7 } & $\mathbf{n}$ & $\mathbf{\%}$ & $\mathbf{n}$ & $\mathbf{\%}$ & $\mathbf{n}$ & $\mathbf{\%}$ \\
\hline \multicolumn{1}{|c|}{ Basic Hygiene } & & & & & & \\
\hline Keeping handkerchief & 87 & 90.6 & 9 & 9.4 & 0 & 0 \\
\hline Covering mouth while coughing & 87 & 90.6 & 9 & 9.4 & 0 & 0 \\
\hline Covering mouth/nose while sneezing & 88 & 91.7 & 1 & 1.0 & 7 & 7.3 \\
\hline Wiping household surfaces & 84 & 87.5 & 11 & 11.5 & 1 & 1.0 \\
\hline Avoiding visiting public places & 60 & 62.5 & 28 & 29.2 & 8 & 8.3 \\
\hline \multicolumn{1}{|c|}{ Using a Mask } & & & & & & \\
\hline Wearing mask at work & & & & & & \\
\hline Wearing mask in crowded place & 19 & 19.8 & 64 & 66.7 & 13 & 13.5 \\
\hline Wearing mask when visiting patient & 75 & 46.9 & 40 & 41.7 & 11 & 12.4 \\
\hline Changing mask daily & 67 & 80.2 & 17 & 17.7 & 2 & 2.0 \\
\hline Covering face when someone coughs & 78 & 81.3 & 17 & 17.7 & 1 & 1.0 \\
\hline
\end{tabular}

Table 4: Practices on Basic Hygiene and Using a Mask

\begin{tabular}{|l|c|c|c|c|c|c|}
\hline \multirow{2}{*}{\multicolumn{1}{|c|}{ Practices }} & \multicolumn{2}{|c|}{ Always } & \multicolumn{2}{c|}{ Sometimes } & \multicolumn{2}{c|}{ Never } \\
\cline { 2 - 7 } & $\mathbf{n}$ & $\mathbf{\%}$ & $\mathbf{n}$ & $\mathbf{\%}$ & $\mathbf{n}$ & $\mathbf{\%}$ \\
\hline Keeping distance $>$ 1m from patients & 53 & 55.2 & 33 & 34.4 & 10 & 10.4 \\
\hline Avoiding crowded places & 38 & 39.6 & 40 & 41.7 & 18 & 18.7 \\
\hline Wash hands immediately on coming home & 81 & 84.4 & 14 & 14.6 & 1 & 1.0 \\
\hline Consciously avoiding touching door handles & 35 & 36.4 & 40 & 41.7 & 21 & 21.9 \\
\hline Avoid touching nose with unwashed hands & 60 & 62.5 & 34 & 35.4 & 2 & 2.1 \\
\hline Shaking hands & 12 & 12.5 & 73 & 76.0 & 11 & 11.5 \\
\hline Hugging & 6 & 6.2 & 59 & 61.5 & 31 & 31.3 \\
\hline Kissing & 9 & 9.4 & 14 & 14.6 & 73 & 76.0 \\
\hline
\end{tabular}

Table 5: Practices on Specific Preventive Measures 


\begin{tabular}{|l|c|c|c|c|c|c|}
\hline \multirow{2}{*}{\multicolumn{1}{|c|}{ Practices }} & \multicolumn{2}{|c|}{ Always } & \multicolumn{2}{c|}{ Sometimes } & \multicolumn{2}{c|}{ Never } \\
\cline { 2 - 8 } & $\mathbf{n}$ & $\mathbf{\%}$ & $\mathbf{n}$ & $\mathbf{\%}$ & $\mathbf{n}$ & $\mathbf{\%}$ \\
\hline \multicolumn{1}{|c|}{ Contracting Flu } & & & & & & \\
\hline Staying home if having cold & 17 & 17.7 & 62 & 64.6 & 17 & 17.7 \\
\hline Visiting doctor at first symptoms & 39 & 40.6 & 41 & 42.7 & 16 & 16.7 \\
\hline Taking prescribed medicines & 49 & 51.0 & 45 & 46.9 & 2 & 2.1 \\
\hline \multicolumn{1}{|c|}{ Educating Others } & & & & & & \\
\hline \multicolumn{1}{|c|}{} & & & & & & \\
\hline Educate others to visit doctor & 60 & 62.5 & 32 & 33.3 & 4 & 4.2 \\
\hline Educate to wash hands frequently & 82 & 85.4 & 13 & 13.6 & 1 & 1.0 \\
\hline Educate to cover faces while coughing & 84 & 87.5 & 11 & 11.5 & 1 & 1.0 \\
\hline
\end{tabular}

Table 6: Practices on Contracting Flu and Educating Others

DISCUSSION: Teachers form an important part of our society which can influence population at large scale. In spite of a pandemic been declared in 2009 and given the importance of schools and teachers in propagating or restricting the epidemic, there are hardly any studies on KAP of teachers in available literature. This study endeavors to fill this gap. It gauges and paves a path to positively change Knowledge, Attitude and Practices (KAP) of school teachers. The venture culminated with an Information, Education and Communication drive in the school, especially concentrating on deficient areas, as detected by this study. Teachers' sound KAP will not only benefit them but also translate into disseminating the same to students and their families resulting in maximum benefit to society. ${ }^{1}$

KNOWLEDGE OF SCHOOL TEACHERS: Most subjects had correct knowledge about basic aspects of H1N1 (causative agent, route of transmission and availability of vaccine). However, some were ignorant about the source of infection. Similar findings are reported in a survey conducted amongst 1, 169 Hong Kong school teachers before school closures due to the H1N1 outbreak in $2009 .{ }^{2}$ In another cross-sectional community based e-mail survey of residents of Sydney during WHO Phase 5 of pandemic in May 2009, it was found that most respondents (96\%) were aware of pandemic, but $44 \%$ felt they did not have enough information about the situation. ${ }^{3}$

In a cross-sectional study on 1,548 adult subjects in Riyadh and Jeddah most participants (95.4\%) were aware of H1N1 being a viral illness but about half the subjects stated that sexual contact was also a mode of transmission and a vaccine was available for disease, though it was not available then. The study indicated that $44 \%$ of all participants had 'low' knowledge about the disease only 5.2\% showed a 'high' level of knowledge. ${ }^{4}$ Another cross-sectional questionnaire based survey conducted in Udaipur (Rajasthan) among 791 individuals (57\% males and 43\% females) in August 2009 reports that $83.1 \%$ respondents had heard about Influenza A (H1N1) but about half felt that they did not have enough information about the pandemic. ${ }^{5}$ The difference in knowledge levels between our study and these studies can be attributed to the fact that these were community based cross sectional surveys and included subjects of varied age groups and educational levels as against our study that included educated teachers.

The present study brings forth the important fact that knowledge of subjects on various aspects of prevention of H1N1 was inadequate. Only less than $2 / 3^{\text {rd }}$ of all subjects appreciated the importance of preventive measures, many didn't know to use the mask correctly or appreciated 
importance of isolating cases. However, in the Australian study only $3.2 \%$ were reluctant to be isolated if infected with "swine flu" while 95.3\% were willing for isolation. Further, only 5.9\% respondents were reluctant to receive a "swine flu" vaccine while $91 \%$ were willing. This shows a sound level of knowledge and better attitude towards prevention in Australia. This could be owing to the fact that Australia is a developed country with a better awareness base. ${ }^{1}$

ATTITUDES OF SCHOOL TEACHERS: More than half the respondents felt that H1N1 is a huge problem. A similar survey amongst teachers and students at University of New South Wales, Sydney, Australia reported that about $2 / 3^{\text {rd }}$ believed it to be serious. ${ }^{1}$ Even though results of our study are quite comparable but higher proportions of Australian teachers believed that it was a serious problem. It could probably be due to the fact that Australian study was conducted in 2009 during the peak of pandemic when the anxiety levels were at the highest.

Interestingly, in the present study only $15.6 \%$ respondents perceived $\mathrm{H} 1 \mathrm{~N} 1$ to be a threat to themselves. The Sydney community study reported a much higher proportion (62\%) ranking their risk of catching influenza during a pandemic as moderate or high. ${ }^{3}$ In the present study about one third subjects felt that H1N1 is being an exaggerated problem rather than a real one. In the Sydney study too, $41.6 \%$ respondents agreed that risk of a pandemic had been exaggerated. ${ }^{3}$ The Udaipur survey found that only $34.5 \%$ respondents felt H1N1 to be a serious threat to their health. ${ }^{5}$ This again talks of a state of better knowledge and correct attitude of the Australians.

The respondents were quite positive in their attitude on H1N1 being preventable as most believed that H1N1 can definitely be prevented. While more than two-thirds believed that wearing mask plays a role in preventing infection, about one-fourth felt that it may play a role. The University of New South Wales, Sydney teachers' survey reports that as many as $21.1 \%$ respondents purchased face masks or hand hygiene products during the epidemic. ${ }^{1}$

The fact that more than two-thirds of subjects believed that they will stay home on having flu is heartening, but more than one fourth believed that they will go to work and stay home only if their symptoms increase. More alarmingly some teachers were defiant and would go to work even if they had symptoms consistent with flu. This is the group, that is required to be targeted during the IEC drive.

PRACTICES OF SCHOOL TEACHERS: It was found that the practices followed by school teachers on basic hygiene were mostly sound and consistent with the principles of prevention. Most believed in keeping a handkerchief, covering their mouth/nose while coughing/ sneezing and wiping household surfaces, as part of preventive strategies. However few felt that they will never cover their mouth / nose while sneezing. The Australian study reports only $8.6 \%$ teachers would avoid busy public places during the epidemic. ${ }^{1}$ In this regard, practices of our teachers are better than their Australian counterparts.

Reluctance was observed amongst teachers to use mask. About two thirds, only sometimes did so. In the Australian study among teachers of New South Wales University, it is reported that the use of masks in public was met with less resistance; only $11.4 \%$ were found to be reluctant to use it and $41.4 \%$ were 'very willing' to use it while $45.3 \%$ were 'willing' to use it.

Few teachers would never take leave even if they suffered from cold and would never visit a doctor at the first symptoms. The figures from the Australian study are more encouraging as $<5 \%$ respondents did not stay away from work (to stay home) when they contacted flu. About half were 
'very willing' to stay away from work while about one third were 'willing' to stay away. Practices of school teachers on educating others about H1N1 were encouraging. Most would always educate others to visit a doctor if they get flu. Contrary to these findings, the Australian study reports that only $6.4 \%$ teachers would approach the individual if someone is coughing /sneezing nearby and educate to comply with specific health measures, e.g. leaving the area, observing respiratory etiquette. ${ }^{1}$

The practices of school teachers on executing specific preventive measures against H1N1 were a mixed bag. The mixed practices indicate that while the knowledge and attitude of the teachers might be acceptable, there is a large gap when it actually comes to practicing them. We need to fill this gap by inculcating the right attitudes and translating them into correct practices if we have to prevent H1N1.

CONCLUSION: The study has important implications for prevention and implementation of infection control measures for H1N1 influenza not only among teachers but also for students being taught by them. The findings indicate that besides enhancing knowledge on preventive aspects of H1N1 there is a requirement of furthering health protective behaviors in teachers and students. As knowledge is associated with practice of health-protective behaviors outbreak control measures should emphasize improving the attitude and practices through active behavior change programmes on H1N1.

In spite of having acceptable knowledge and attitude, positive behavioral response to H1N1 was poor. This gap between good knowledge and attitudes not being translated to robust practices needs to be bridged, and let's begin with teachers, as they are the harbingers of change in a society.

ACKNOWLEDGEMENTS AND DECLARATION: We declare that no competing interest exists The study did not receive any funding from any agency.

\section{REFERENCES:}

1. Van D, McLaws ML, Crimmins J, MacIntyre C R, Seale H. University life and pandemic influenza: Attitudes and intended behaviour of staff and students towards pandemic (H1N1) 2009. BMC Public Health 2010, 10:130.

2. Wong EM, Cheng MM, Lo SK. Teachers' Risk Perception and Needs in Addressing Infectious Disease Outbreak. J Sch Nurs. 2010 Jun 18.

3. Seale H, McLaws ML, Heywood AE, Ward KF, Lowbridge CP, Van D, Gralton J, MacIntyre R. The community's attitude towards swine flu and pandemic influenza. Med J Australia. 2009; 191 (5): 267-269.

4. Balkhy HH, Abolfotouh MA, Al-Hathlool RH, Al-Jumah MA. Awareness, attitudes, and practices related to the swine influenza pandemic among the Saudi public. BMC Infectious Diseases 2010, 10:42

5. Kamte SS, Agrawal A, Chaudhary H, Singh K, Mishra P, Asawa K. Public knowledge, attitude and behavioural changes in an Indian population during the Influenza A (H1N1) outbreak. J Infect Dev Ctries 2010; 4(1):007-014. 


\section{ORIGINAL ARTICLE}

\section{AUTHORS:}

1. Avtar Singh Bansal

2. R.K. Gupta

3. Rajshree R. Gupta

\section{PARTICULARS OF CONTRIBUTORS:}

1. Associate Professor, Department of Community Medicine, Adesh Institute of Medical Sciences and Research, Bathinda, Punjab.

2. Professor, Department of Community Medicine, ACMS, Delhi.

3. Project Manager, Med Education, $\mathrm{AD}$ Instruments, New Delhi.
NAME ADDRESS EMAIL ID OF THE

\section{CORRESPONDING AUTHOR:}

Dr. Avtar Singh Bansal,

Department of Community Medicine,

Adesh Institute of Medical Sciences and Research, Bathinda, Punjab - 151109.

Email - avtarsinghbansal@gmail.com

Date of Submission: 20/12/2013.

Date of Peer Review: 21/12/2013.

Date of Acceptance: 07/01/2014.

Date of Publishing: 16/01/2014. 